\title{
OCORRÊNCIA DE VERANICOS EM BELO HORIZONTE: O EPISÓDIO DE 23/12/2014 A 21/01/2015
}

\author{
Marina Rozendo Silva ${ }^{(\mathrm{a})}$; Alexsandro S. Oliveira ${ }^{(\mathrm{b})}$; Carlos Henrique Jardim ${ }^{(\mathrm{c})}$ \\ (a) Mestranda, Depto. Geografia/IGC/UFMG, marinarozendo@yahoo.com.br \\ (b) Graduando, Depto. Geografia/IGC/UFMG, alexsandro.oliveira@educacao.mg.gov \\ (c) Docente, Depto. Geografia/IGC/UFMG, dxhenrique@gmail.com
}

\section{Eixo: Climatologia em Diferentes Níveis Escalares: Mudanças e Variabilidades}

\begin{abstract}
Resumo
O objetivo do presente artigo é compreender a gênese e as características dos eventos de veranicos em Belo Horizonte, considerando inicialmente o episódio entre os dias 23/12/2014 a 21/01/2015. Esses eventos, marcados pela ausência de chuvas durante o período chuvoso, pode acarretar uma série de problemas como dificuldade de abastecimento de água e aumento de preços dos produtos agrícolas. Para efeito de análise foram utilizadas imagens de satélite e cartas sinóticas, bem como informações relativas ao evento recolhidas da internet. Os resultados mostraram que a permanência de sistemas estáveis sobre uma dada região ou localidade é o principal fator por trás de seu desencadeamento, cuja intensidade pode ser reforçada por mecanismos atmosféricos de larga escala.
\end{abstract}

Palavras chave: seca; variabilidade climática; impactos ambientais.

\section{Introdução}

O ambiente é utilizado de diversas formas pelas sociedades humanas ao longo do tempo. Além de suporte físico, é dele que as sociedades extraem todo tipo de recursos necessários à sua sobrevivência (água, minerais, alimentos, energia etc.). Entretanto, o crescimento das cidades e expansão das economias exigem novas formas de relação com o ambiente. A necessidade de compreender os mecanismos naturais articulados com as demandas sociais é fundamental para se evitar catástrofes como aquelas ocorridas no vale do Rio Itajaí em Santa Catarina em 2005 e a "crise hídrica" em 2014 que afetou o sudeste brasileiro. Tanto o excesso quanto a ausência de chuvas por períodos relativamente longos constituem-se em aspectos recorrentes da variabilidade climática, denunciados pela análise de qualquer série temporal de dados de chuva de qualquer localidade do Brasil e do mundo, e sua compreensão é fundamental para o planejamento de ações, sem necessidade de evocar explicações catastróficas sobre mudanças climáticas.

O clima de Belo Horizonte, segundo Nimer (1989), caracteriza-se pelo tipo Tropical Subquente SemiÚmido, com período chuvoso entre outubro e março e período seco entre abril e setembro, com o segundo contribuindo com menos de $20 \%$ da pluviosidade anual. O trimestre dezembro/janeiro/fevereiro é responsável por mais da metade das chuvas no ano. Entretanto, essa dinâmica é muito irregular, sujeita a 
variações importantes dentro do qual se configuram os veranicos. Trata-se de fenômeno relativamente comum quando pensando em termos de escala temporal dilatada (várias décadas seguidas). Por outro lado, um único episódio pode causar prejuízos financeiros, econômicos e sociais, com impactos negativos, sobretudo em regiões mais vulneráveis desprovidas de sistemas mais eficientes de abastecimento de água.

Esses impactos se configuram como negativos em decorrência de ocupação recente e efeitos de urbanização mal planejada e executada. Kobiyama et al. (2006) relata que a prevenção desses eventos chega a ser até 30 vezes mais rentável que com remediações.

O período chuvoso em Minas Gerais ocorre habitualmente entre os meses de outubro e março e está associado a ação de sistemas Frontais (SF), linhas de instabilidades (LI), Zona de Convergência de Umidade/Zona de Convergência do Atlântico Sul (ZCOU/ZCAS) e sistemas convectivos (MOREIRA e ABREU, 2002). No período de seca, habitualmente entre abril e setembro, as condições de estabilidade atmosférica são ditadas pela ação do Anticiclone Subtropical do Atlântico Sul (ASAS) e, secundariamente, pelo Anticiclone Polar Atlântico (APA). As condições descritas, na verdade, podem ocorrer em qualquer período do ano, de forma mais ou menos intensificada, constituindo-se em aspectos a ser compreendido dentro do que Monteiro (1971) define por "ritmo climático".

O objetivo deste artigo é compreender a gênese e as características dos eventos de veranicos e sua repercussão sobre a cidade de Belo Horizonte, utilizando inicialmente como exemplo o episódio ocorrido entre 23 de dezembro de 2014 a 21 de janeiro de 2015, em função da ausência de chuvas e impactos no abastecimento hídrico na cidade, com rodízio de distribuição de água entre os bairros.

\section{Procedimentos Metodológicos}

A fonte principal de dados incluiu as séries históricas de dados de chuva de Belo Horizonte, obtidas através do site do Instituto Nacional de Meteorologia - INMET (www.inmet.gov.br) abrangendo o período entre 1961-2016 da estação situada na Avenida do Contorno com a Av. Raja Gabáglia (área central de Belo Horizonte $-19,93^{\circ} \mathrm{S}$ e $43,93^{\circ} \mathrm{W}$ - altitude de $915 \mathrm{~m}$ ).

Inicialmente os episódios de seca dentro do período chuvoso foram selecionados com base na pesquisa de Silva et al. (2017) que definiu como valores extremos negativos (seco e super seco) para os meses de dezembro, janeiro e fevereiro, respectivamente, os valores iguais ou inferiores a $143 \mathrm{~mm}, 61,3 \mathrm{~mm}$ e 47,9 mm. De acordo com dados das Normais Climatológicas 1961-1990 (DNMET, 1992) as médias desses meses são 292 mm, 274,1 mm e 206,3 mm. Esses valores constituíram-se em indicativos de meses com pouca chuva para, a partir daí, selecionar os episódios de veranicos. 


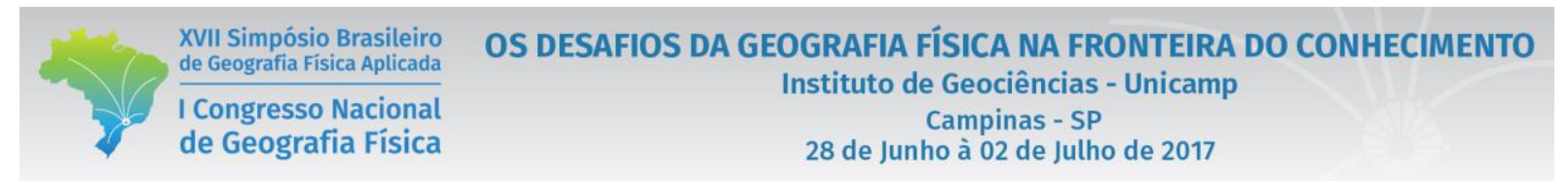

A identificação dos sistemas atmosféricos atuantes durante os episódios de veranico deu-se a partir da análise das cartas sinóticas produzidas pela Marinha do Brasil (www.marinha.mil.br), considerando os valores do campo de pressão atmosférica em superfície, em conjunto com imagens de satélite meteorológico do Instituto Nacional de Pesquisas Espaciais (www.inpe.br) considerando elementos de nebulosidade nas imagens produzidas nos canais infravermelho e visível. De forma subsidiária consultouse, também, dados de mídia escrita e digital (internet) úteis na descrição dos impactos e dos períodos de atuação.

\section{Resultados}

No período compreendido pela análise, que se iniciou no dia 23 de dezembro de 2014 e terminou no dia 21 de janeiro do ano seguinte, o total de chuvas foi de apenas 0,8 $\mathrm{mm}$ (figura 1). Nesses meses, particularmente, choveu 138,1 mm em dezembro e 103,8 mm em janeiro. Portanto, em ambos os casos, os totais ficaram abaixo da média climatológica de $292 \mathrm{~mm}$ e $274,1 \mathrm{~mm}$, respectivamente. E não apenas nesses meses, mas no ano de 2014 as chuvas situaram-se abaixo das médias (944,1 mm contra 1463,7 $\mathrm{mm})$.

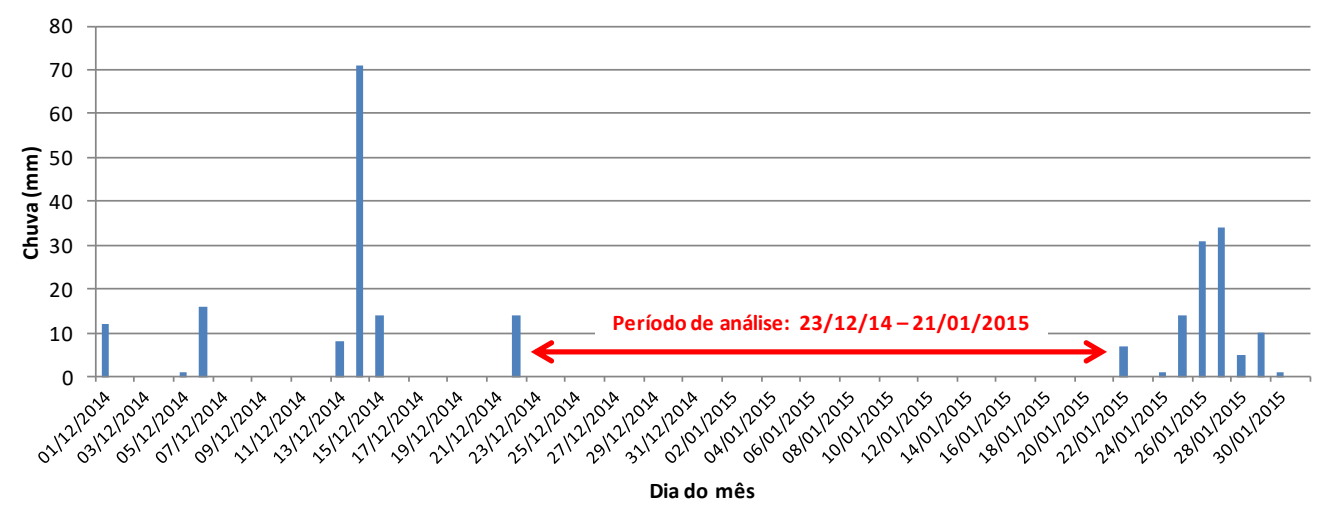

Figura 1 - Variação diária das chuvas durante os meses de dezembro de 2014 e janeiro de 2015. Fonte: INMET <www.inmet.gov.br>. Acesso: 11 mar. 2017. Org.: Carlos H. Jardim

A partir das cartas sinóticas associadas às imagens de satélite (figura 2), pode-se observar a atuação do Anticiclone Subtropical do Atlântico Sul (ASAS), nessa época do ano, na região de estudo. A ação desse sistema constitui-se em fato habitual, pois sua ação ocorre em todos os meses do ano em Belo Horizonte, denunciada pelos ventos de leste. Fato incomum, marcado por desvio, foi sua permanência durante o longo período indicado (sem duração precisa, atuando entre10 a 30 dias). De acordo com informações da análise sinótica do CPTEC-INPE (http://www.cptec.inpe.br/ rupload/arquivo/analise_01012015.pdf), a 


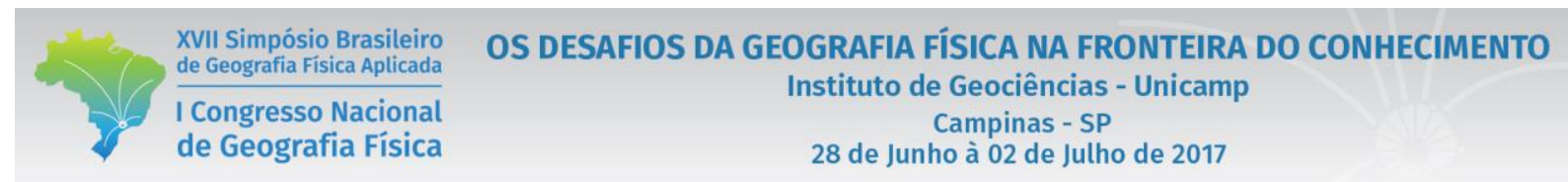

título de exemplo da configuração sinótica na ocasião do veranico, o valor de pressão em superfície do ASAS no dia 01/01/2015 era de $1020 \mathrm{hPa}$ e os sistemas frontais nas proximidades possuíam fraco valor de pressão (1004 hPa) incapaz de romper o bloqueio imposto pelo ASAS e a ZCIT (Zona de Convergência Intertropical) oscilava no hemisfério norte entre as latitudes de $5^{\circ}$ e $6^{\circ}$.

A coluna de ar descendente é acompanhada de compressão e aquecimento adiabático inibindo a formação de nuvens com grande desenvolvimento vertical e chuvas. $\mathrm{O}$ aumento da pressão em superfície e o baixo gradiente de pressão descrito anteriormente para os sistemas frontais e a posição da ZCIT, reforçam as condições de bloqueio, mantendo esses sistemas distantes da área de influência do ASAS.
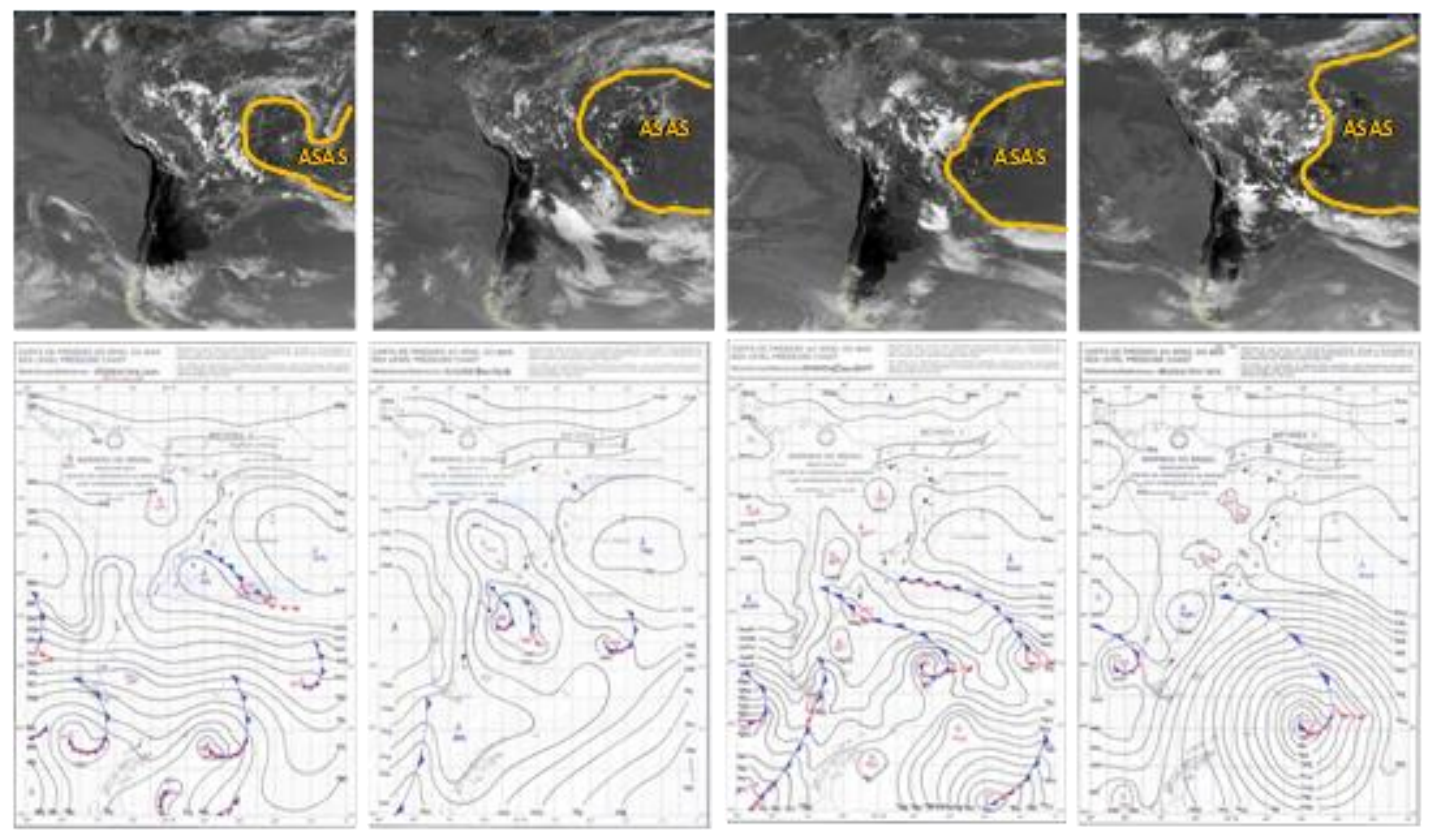

Figura 2 - Imagens de satélite meteorológico e cartas sinóticas dos dias 25/12, 01/01, 09/01 e 17/01/2015. Fonte: www.cptec.inpe.br; www.mar.mil.br. Acesso: 11 mar. 2017. Org.: Carlos H. Jardim.

Outra informação importante refere-se à ação do El Niño nesse ano de 2014/2015, cujo estabelecimento reforça a ação desse sistema de alta pressão aumentando a duração das estiagens na região norte e nordeste (principalmente), afetando ocasionalmente o centro-oeste e sudeste brasileiro, reiterado, também, em pesquisa anterior executada por Cupolillo (2002).

A atuação desse sistema produziu impactos generalizados sobre grande parte do território mineiro conforme veiculado na mídia. De acordo com o portal de notícias "Uai" sobre notícia do jornal Estado Minas (http://www.em.com.br/gerais/) no dia 07/01/2015 com título “Seca em Minas Gerais pode ser pior em 2015". De acordo com a matéria foram relatados problemas com níveis de água em vários 
reservatórios, como o do Retiro Baixo no rio Paraopeba entre Pompéu e Curvelo e de várias usinas de fornecimento de energia elétrica (Baguarí, próximo a Governador Valadares e na usina de Queimado em Unaí).

\section{Considerações Finais}

O aprofundamento de pesquisas para compreensão da dinâmica das chuvas é necessário e embora cada evento revista-se de características próprias, a ocorrência de veranicos é fato reconhecido há muito tempo por diversos pesquisadores sobre a climatologia do sudeste brasileiro. Sendo assim porque uma região com essas especificidades não possui uma política de prevenção?

Não existe uma única resposta para essa questão, mas sem dúvida toca nas questões que envolvem infraestrutura precária e planejamento estatal ineficiente conforme relatado por Jardim (2012; 2015).

\section{Bibliografia}

CUPOLILLO, F.; BRITES, R. S.; PRATES, J. E. Espacialização de Veranico em Minas Gerais - Período de 1968 1988. In: Anais... XII Congresso Brasileiro de Meteorologia, Foz de Iguaçu-PR, 2002. 287-294 p.

DNMET. Departamento Nacional de Meteorologia. Normais Climatológicas (1961- 1990). Brasília-DF, 1992.

JARDIM, C. H. "Médias" e "desvios" na análise geográfico-climatológica: o episódio de chuva concentrada do dia 23 de novembro de 2010 e o veranico de janeiro/fevereiro de 2011 em Belo Horizonte - MG. Geografias, Belo Horizonte 08(2) 35-49 jan-jun. 2012.

JARDIM, C. H. A "crise hídrica" no sudeste do Brasil: aspectos climáticos e repercussões ambientais. Tamoios, São Gonçalo (RJ), ano 11, n. 2, p.67-83, jul/dez. 2015.

KOBIYAMA, M; MENDONÇA, M; MORENO, D. A; PENA, I; MARCELINO, V. O; MARCELINO, E. V; GONÇALVES, E. F; BRAZETTI, L. L. P; GOERL, R. F; MOLLERI, G. S. F; RUDORFF, F. M. Prevenção de desastres naturais: conceitos básicos. 1.ed. Florianópolis: Ed. Organic Trading , 2006.

MONTEIRO, C. A. F. Análise rítmica em climatologia. Problemas da atualidade climática em São Paulo e achegas para um programa de trabalho. Climatologia, São Paulo, n.01, p.1-21, 1971.

MOREIRA, J. L. B; ABREU, M. L. Distribuição espacial da precipitação sobre a Região Metropolitana de Belo Horizonte - MG e sua associação com a topografia local. In: CONGRESSO BRASILEIRO DE METEOROLOGIA, 12, 2002, Foz do Iguaçu. Anais... Foz do Iguaçu: Congresso Brasileiro de Meteorologia, 2002. Disponível em: < http://www.cbmet.com/edicoes.php?pageNum_Recordset_busca=4\&totalRows_Recordset_busca=559\&cgid=11> Acesso em: 06 fev. 2017.

NIMER, E. Climatologia do Brasil. Rio de Janeiro: IBGE, 1989.

SILVA, M. R; MOURA, F. P; JARDIM, C. H. O diagrama de Caixa (Box Plot) Aplicado à Análise da Distribuição Temporal das Chuvas em Januária, Belo Horizonte e Sete Lagoas, Minas Gerais-Brasil. Revista Brasileira de Geografia Física (In press) v. 10, n.1, 2017. 